\title{
General uniqueness theorem concerning the stability of additive, quadratic, and cubic functional equations
}

Yang-Hi Lee' and Soon-Mo Jung ${ }^{2 *}$

\section{"Correspondence:}

smjung@hongik.ac.kr

${ }^{2}$ Mathematics Section, College of

Science and Technology, Hongik

University, Sejong, 30016, Republic of Korea

Full list of author information is

available at the end of the article

\begin{abstract}
We prove a general uniqueness theorem that can easily be applied to the proof of (generalized) Hyers-Ulam stability of the additive, quadratic, cubic, or the cubic-quadratic-additive type functional equation. By using this uniqueness theorem, we can omit the repeated proof for uniqueness of the relevant solutions of those equations.
\end{abstract}

MSC: Primary 39B82; secondary 39B52

Keywords: generalized Hyers-Ulam stability; uniqueness; cubic-quadratic-additive type functional equation; cubic-quadratic-additive mapping

\section{Introduction}

In 1940, Ulam [1] posed a problem concerning the stability of functional equations: Give conditions in order for a linear function near an approximately linear function to exist. A year later, Hyers [2] gave an answer to the problem of Ulam for additive functions defined on Banach spaces. After Hyers' result, many mathematicians have extended Ulam's problem to other functional equations and generalized Hyers' result in various directions (see [3-7]).

Let $V$ and $W$ be real vector spaces. For a given mapping $f: V \rightarrow W$, we define

$$
\begin{aligned}
& A f(x, y):=f(x+y)-f(x)-f(y), \\
& Q f(x, y):=f(x+y)-2 f(x)+f(x-y)-2 f(y), \\
& C f(x, y):=f(x+2 y)-3 f(x+y)+3 f(x)-f(x-y)-6 f(y), \\
& f_{o}(x):=\frac{f(x)-f(-x)}{2} \\
& f_{o}^{(1)}(x):=\frac{a^{3} f_{o}(x)-f_{o}(a x)}{a^{3}-a} \\
& f_{o}^{(2)}(x):=-\frac{a f_{o}(x)-f_{o}(a x)}{a^{3}-a} \\
& f_{e}(x):=\frac{f(x)+f(-x)}{2}
\end{aligned}
$$

(c) 2016 Lee and Jung. This article is distributed under the terms of the Creative Commons Attribution 4.0 International License (http://creativecommons.org/licenses/by/4.0/), which permits unrestricted use, distribution, and reproduction in any medium, provided you give appropriate credit to the original author(s) and the source, provide a link to the Creative Commons license, and indicate if changes were made. 
for all $x, y \in V$. A mapping $f: V \rightarrow W$ is called an additive mapping, a quadratic mapping, and a cubic mapping if $f$ satisfies the functional equation $A f(x, y)=0, Q f(x, y)=0$, and $C f(x, y)=0$ for all $x, y \in V$, respectively. We remark that the mappings $g, h, k: \mathbf{R} \rightarrow \mathbf{R}$ given by $g(x)=a x, h(x)=a x^{2}$, and $k(x)=a x^{3}$ are solutions of $A g(x, y)=0, Q h(x, y)=0$, and $C k(x, y)=0$, respectively.

A mapping $f: V \rightarrow W$ is called a cubic-quadratic-additive mapping if and only if $f$ is represented by the sum of an additive mapping, a quadratic mapping, and a cubic mapping. A functional equation is called a cubic-quadratic-additive type functional equation if and only if each of its solutions is a cubic-quadratic-additive mapping. The mapping $f: \mathbf{R} \rightarrow \mathbf{R}$ given by $f(x)=a x^{3}+b x^{2}+c x$ is a solution of the cubic-quadratic-additive type functional equation.

In the study of the stability problems for cubic-quadratic-additive type functional equations, we frequently encounter the cases where we should prove the uniqueness of the cubic-quadratic-additive mappings (see [8-18]). Research in this uniqueness problem still has many untouched possibilities to explore.

In this paper, we prove a general uniqueness theorem that can be easily applied to the stability of the cubic-quadratic-additive type functional equations. Using this uniqueness theorem, we do not need to repeat the proof of uniqueness in studying the stability of functional equations mentioned above.

\section{Main results}

In this section, let $X$ and $Y$ be real normed spaces and let $V$ and $W$ be real vector spaces. In the following theorem, we prove that if, for any given mapping $f$, there exists a mapping $F$ (near $f$ ) with some properties possessed by cubic-quadratic-additive mappings, then the mapping $F$ must be uniquely determined.

Theorem 2.1 Let $a>1$ be a real constant, let $\Phi: V \backslash\{0\} \rightarrow[0, \infty)$ be a function satisfying one of the following conditions:

$$
\begin{aligned}
& \lim _{n \rightarrow \infty} \frac{\Phi\left(a^{n} x\right)}{a^{n}}=0, \\
& \lim _{n \rightarrow \infty} a^{n} \Phi\left(\frac{x}{a^{n}}\right)=\lim _{n \rightarrow \infty} \frac{\Phi\left(a^{n} x\right)}{a^{2 n}}=0, \\
& \lim _{n \rightarrow \infty} a^{2 n} \Phi\left(\frac{x}{a^{n}}\right)=\lim _{n \rightarrow \infty} \frac{\Phi\left(a^{n} x\right)}{a^{3 n}}=0, \\
& \lim _{n \rightarrow \infty} a^{3 n} \Phi\left(\frac{x}{a^{n}}\right)=0
\end{aligned}
$$

for all $x \in V \backslash\{0\}$, and let $f: V \rightarrow Y$ be a given mapping. If there exists a mapping $F: V \rightarrow Y$ such that

$$
\|f(x)-F(x)\| \leq \Phi(x)
$$

for all $x \in V \backslash\{0\}$ and

$$
F_{o}^{(1)}(a x):=a F_{o}^{(1)}(x), \quad F_{e}(a x):=a^{2} F_{e}(x), \quad F_{o}^{(2)}(a x):=a^{3} F_{o}^{(2)}(x)
$$


for all $x \in V$, then $F$ is given by

$$
F(x)= \begin{cases}\lim _{n \rightarrow \infty}\left(\frac{f_{o}^{(1)}\left(a^{n} x\right)}{a^{n}}+\frac{f_{e}\left(a^{n} x\right)}{a^{2 n}}+\frac{f_{o}^{(2)}\left(a^{n} x\right)}{a^{3 n}}\right) & \text { if } \Phi \text { satisfies (1), } \\ \lim _{n \rightarrow \infty}\left(a^{n} f_{o}^{(1)}\left(\frac{x}{a^{n}}\right)+\frac{f_{e}\left(a^{n} x\right)}{a^{2 n}}+\frac{f_{o}^{(2)}\left(a^{n} x\right)}{a^{3 n}}\right) & \text { if } \Phi \text { satisfies (2), } \\ \lim _{n \rightarrow \infty}\left(a^{n} f_{o}^{(1)}\left(\frac{x}{a^{n}}\right)+a^{2 n} f_{e}\left(\frac{x}{a^{n}}\right)+\frac{f_{o}^{(2)}\left(a^{n} x\right)}{a^{3 n}}\right) & \text { if } \Phi \text { satisfies (3), } \\ \lim _{n \rightarrow \infty}\left(a^{n} f_{o}^{(1)}\left(\frac{x}{a^{n}}\right)+a^{2 n} f_{e}\left(\frac{x}{a^{n}}\right)+a^{3 n} f_{o}^{(2)}\left(\frac{x}{a^{n}}\right)\right) & \text { if } \Phi \text { satisfies (4) }\end{cases}
$$

for all $x \in V \backslash\{0\}$. In other words, $F$ is the unique mapping satisfying the conditions (5) and (6).

Proof Assume that $F$ is a mapping satisfying (5) and (6) for a given mapping $f: V \rightarrow Y$. First, we consider the mapping $F_{o}^{(1)}$. If $\Phi: V \backslash\{0\} \rightarrow[0, \infty)$ satisfies the condition (1), then it follows from (6) that

$$
\begin{aligned}
&\left\|F_{o}^{(1)}(x)-\frac{f_{o}^{(1)}\left(a^{n} x\right)}{a^{n}}\right\| \\
&=\frac{1}{a^{n}}\left\|F_{o}^{(1)}\left(a^{n} x\right)-f_{o}^{(1)}\left(a^{n} x\right)\right\| \\
&=\frac{1}{2\left(a^{3}-a\right) a^{n}} \| a^{3} F\left(a^{n} x\right)-a^{3} f\left(a^{n} x\right)-a^{3} F\left(-a^{n} x\right)+a^{3} f\left(-a^{n} x\right) \\
&-F\left(a^{n+1} x\right)+f\left(a^{n+1} x\right)+F\left(-a^{n+1} x\right)-f\left(-a^{n+1} x\right) \| \\
& \leq \frac{1}{2\left(a^{3}-a\right) a^{n}}\left(a^{3}\left\|F\left(a^{n} x\right)-f\left(a^{n} x\right)\right\|+a^{3}\left\|F\left(-a^{n} x\right)-f\left(-a^{n} x\right)\right\|\right. \\
&\left.+\left\|F\left(a^{n+1} x\right)-f\left(a^{n+1} x\right)\right\|+\left\|F\left(-a^{n+1} x\right)-f\left(-a^{n+1} x\right)\right\|\right) \\
& \leq \frac{a^{3} \Phi\left(a^{n} x\right)+a^{3} \Phi\left(-a^{n} x\right)+\Phi\left(a^{n+1} x\right)+\Phi\left(-a^{n+1} x\right)}{2\left(a^{3}-a\right) a^{n}} \\
& \rightarrow 0, \quad \text { as } n \rightarrow \infty
\end{aligned}
$$

for all $x \in V \backslash\{0\}$; that is, we see that $F_{o}^{(1)}(x)=\lim _{n \rightarrow \infty} \frac{1}{a^{n}} f_{o}^{(1)}\left(a^{n} x\right)$ for all $x \in V \backslash\{0\}$.

If $\Phi: V \backslash\{0\} \rightarrow[0, \infty)$ satisfies the condition (2), (3), or (4), then it follows from (6) that

$$
\begin{aligned}
\left\|F_{o}^{(1)}(x)-a^{n} f_{o}^{(1)}\left(\frac{x}{a^{n}}\right)\right\| \\
=a^{n}\left\|F_{o}^{(1)}\left(\frac{x}{a^{n}}\right)-f_{o}^{(1)}\left(\frac{x}{a^{n}}\right)\right\| \\
=\frac{a^{n}}{2\left(a^{3}-a\right)} \| a^{3} F\left(\frac{x}{a^{n}}\right)-a^{3} f\left(\frac{x}{a^{n}}\right)-a^{3} F\left(\frac{-x}{a^{n}}\right)+a^{3} f\left(\frac{-x}{a^{n}}\right) \\
\quad-F\left(\frac{x}{a^{n-1}}\right)+f\left(\frac{x}{a^{n-1}}\right)+F\left(\frac{-x}{a^{n-1}}\right)-f\left(\frac{-x}{a^{n-1}}\right) \| \\
\leq \frac{a^{n}}{2\left(a^{3}-a\right)}\left(a^{3}\left\|F\left(\frac{x}{a^{n}}\right)-f\left(\frac{x}{a^{n}}\right)\right\|+a^{3}\left\|F\left(\frac{-x}{a^{n}}\right)-f\left(\frac{-x}{a^{n}}\right)\right\|\right. \\
\left.\quad+\left\|F\left(\frac{x}{a^{n-1}}\right)-f\left(\frac{x}{a^{n-1}}\right)\right\|+\left\|F\left(\frac{-x}{a^{n-1}}\right)-f\left(\frac{-x}{a^{n-1}}\right)\right\|\right)
\end{aligned}
$$




$$
\begin{aligned}
& \leq \frac{1}{2\left(a^{3}-a\right)}\left(a^{n+3} \Phi\left(\frac{x}{a^{n}}\right)+a^{n+3} \Phi\left(\frac{-x}{a^{n}}\right)+a^{n} \Phi\left(\frac{x}{a^{n-1}}\right)+a^{n} \Phi\left(\frac{-x}{a^{n-1}}\right)\right) \\
& \rightarrow 0, \quad \text { as } n \rightarrow \infty
\end{aligned}
$$

for all $x \in V \backslash\{0\}$; that is, we see that $F_{o}^{(1)}(x)=\lim _{n \rightarrow \infty} a^{n} f_{o}^{(1)}\left(\frac{x}{a^{n}}\right)$ for all $x \in V \backslash\{0\}$.

Second, we consider the mapping $F_{e}$. If $\Phi: V \backslash\{0\} \rightarrow[0, \infty)$ satisfies the condition (1) or (2), then it follows from (6) that

$$
\begin{aligned}
& \left\|F_{e}(x)-\frac{f_{e}\left(a^{n} x\right)}{a^{2 n}}\right\| \\
& \quad=\frac{1}{a^{2 n}}\left\|F_{e}\left(a^{n} x\right)-f_{e}\left(a^{n} x\right)\right\|=\frac{1}{2 a^{2 n}}\left\|F\left(a^{n} x\right)-f\left(a^{n} x\right)+F\left(-a^{n} x\right)-f\left(-a^{n} x\right)\right\| \\
& \leq \frac{1}{2 a^{2 n}}\left\|F\left(a^{n} x\right)-f\left(a^{n} x\right)\right\|+\frac{1}{2 a^{2 n}}\left\|F\left(-a^{n} x\right)-f\left(-a^{n} x\right)\right\| \\
& \quad \leq \frac{\Phi\left(a^{n} x\right)+\Phi\left(-a^{n} x\right)}{2 a^{2 n}} \\
& \quad \rightarrow 0, \quad \text { as } n \rightarrow \infty
\end{aligned}
$$

for all $x \in V \backslash\{0\}$; that is, we see that $F_{e}(x)=\lim _{n \rightarrow \infty} \frac{1}{a^{2 n}} f_{e}\left(a^{n} x\right)$ for all $x \in V \backslash\{0\}$.

If $\Phi: V \rightarrow[0, \infty)$ satisfies the condition (3) or (4), we get

$$
\begin{aligned}
& \left\|F_{e}(x)-a^{2 n} f_{e}\left(\frac{x}{a^{n}}\right)\right\| \\
& =a^{2 n}\left\|F_{e}\left(\frac{x}{a^{n}}\right)-f_{e}\left(\frac{x}{a^{n}}\right)\right\| \\
& =\frac{a^{2 n}}{2}\left\|F\left(\frac{x}{a^{n}}\right)-f\left(\frac{x}{a^{n}}\right)+F\left(\frac{-x}{a^{n}}\right)-f\left(\frac{-x}{a^{n}}\right)\right\| \\
& \leq \frac{a^{2 n}}{2}\left\|F\left(\frac{x}{a^{n}}\right)-f\left(\frac{x}{a^{n}}\right)\right\|+\frac{a^{2 n}}{2}\left\|F\left(\frac{-x}{a^{n}}\right)-f\left(\frac{-x}{a^{n}}\right)\right\| \\
& \leq \frac{a^{2 n}}{2}\left(\Phi\left(\frac{x}{a^{n}}\right)+\Phi\left(\frac{-x}{a^{n}}\right)\right) \\
& \rightarrow 0, \quad \text { as } n \rightarrow \infty
\end{aligned}
$$

for all $x \in V \backslash\{0\}$. Then $F_{e}(x)=\lim _{n \rightarrow \infty} a^{2 n} f_{e}\left(\frac{x}{a^{n}}\right)$ for all $x \in V \backslash\{0\}$ holds.

Finally, we consider the mapping $f_{o}^{(2)}$. If $\Phi: V \backslash\{0\} \rightarrow[0, \infty)$ satisfies the condition (1), (2), or (3), then it follows from (6) that

$$
\begin{aligned}
&\left\|F_{o}^{(2)}(x)-\frac{f_{o}^{(2)}\left(a^{n} x\right)}{a^{3 n}}\right\| \\
&=\frac{1}{a^{3 n}}\left\|F_{o}^{(2)}\left(a^{n} x\right)-f_{o}^{(2)}\left(a^{n} x\right)\right\| \\
&=\frac{1}{2\left(a^{3}-a\right) a^{3 n}} \|-a F\left(a^{n} x\right)+a f\left(a^{n} x\right)+a F\left(-a^{n} x\right)-a f\left(-a^{n} x\right) \\
& \quad+F\left(a^{n+1} x\right)-f\left(a^{n+1} x\right)-F\left(-a^{n+1} x\right)+f\left(-a^{n+1} x\right) \| \\
& \leq \frac{1}{2\left(a^{3}-a\right) a^{3 n}}\left(a\left\|F\left(a^{n} x\right)-f\left(a^{n} x\right)\right\|+a\left\|F\left(-a^{n} x\right)-f\left(-a^{n} x\right)\right\|\right.
\end{aligned}
$$




$$
\begin{aligned}
& \left.+\left\|F\left(a^{n+1} x\right)-f\left(a^{n+1} x\right)\right\|+\left\|F\left(-a^{n+1} x\right)-f\left(-a^{n+1} x\right)\right\|\right) \\
\leq & \frac{a \Phi\left(a^{n} x\right)+a \Phi\left(-a^{n} x\right)+\Phi\left(a^{n+1} x\right)+\Phi\left(-a^{n+1} x\right)}{2\left(a^{3}-a\right) a^{3 n}} \\
\rightarrow & 0, \quad \text { as } n \rightarrow \infty
\end{aligned}
$$

for all $x \in V \backslash\{0\}$; that is, we see that $F_{o}^{(2)}(x)=\lim _{n \rightarrow \infty} \frac{1}{a^{3 n}} f_{o}^{(2)}\left(a^{n} x\right)$ for all $x \in V \backslash\{0\}$.

If $\Phi: V \backslash\{0\} \rightarrow[0, \infty)$ satisfies the condition (4), then it follows from (4) and (6) that

$$
\begin{aligned}
\left\|F_{o}^{(2)}(x)-a^{3 n} f_{o}^{(2)}\left(\frac{x}{a^{n}}\right)\right\| \\
=a^{3 n}\left\|F_{o}^{(2)}\left(\frac{x}{a^{n}}\right)-f_{o}^{(2)}\left(\frac{x}{a^{n}}\right)\right\| \\
=\frac{a^{3 n}}{2\left(a^{3}-a\right)} \|-a F\left(\frac{x}{a^{n}}\right)+a f\left(\frac{x}{a^{n}}\right)+a F\left(\frac{-x}{a^{n}}\right)-a f\left(\frac{-x}{a^{n}}\right) \\
\quad+F\left(\frac{x}{a^{n-1}}\right)-f\left(\frac{x}{a^{n-1}}\right)-F\left(\frac{-x}{a^{n-1}}\right)+f\left(\frac{-x}{a^{n-1}}\right) \| \\
\leq \frac{a^{3 n}}{2\left(a^{3}-a\right)}\left(a\left\|F\left(\frac{x}{a^{n}}\right)-f\left(\frac{x}{a^{n}}\right)\right\|+a\left\|F\left(\frac{-x}{a^{n}}\right)-f\left(\frac{-x}{a^{n}}\right)\right\|\right. \\
\left.\quad+\left\|F\left(\frac{x}{a^{n-1}}\right)-f\left(\frac{x}{a^{n-1}}\right)\right\|+\left\|F\left(\frac{-x}{a^{n-1}}\right)-f\left(\frac{-x}{a^{n-1}}\right)\right\|\right) \\
\leq \frac{a^{3 n}}{2\left(a^{3}-a\right)}\left(a \Phi\left(\frac{x}{a^{n}}\right)+a \Phi\left(\frac{-x}{a^{n}}\right)+\Phi\left(\frac{x}{a^{n-1}}\right)+\Phi\left(\frac{-x}{a^{n-1}}\right)\right) \\
\rightarrow 0, \quad \text { as } n \rightarrow \infty
\end{aligned}
$$

for all $x \in V \backslash\{0\}$; that is, we see that $F_{o}^{(2)}(x)=\lim _{n \rightarrow \infty} a^{3 n} f_{o}^{(2)}\left(\frac{x}{a^{n}}\right)$ for all $x \in V \backslash\{0\}$. Since $F(x)=F_{o}^{(1)}(x)+F_{e}(x)+F_{o}^{(2)}(x), F$ is given by the equalities in (7) and $F$ is uniquely determined for any case.

In general, it is not easy to apply Theorem 2.1 for practical applications. Hence, we introduce a couple of corollaries which are useful for investigating the uniqueness problems in the stability of the cubic-quadratic-additive functional equations.

Corollary 2.2 Let $a>1$ be a real constant and let $\phi: V \backslash\{0\} \rightarrow[0, \infty)$ be a function satisfying either

$$
\Phi(x):=\sum_{i=0}^{\infty} \frac{\phi\left(a^{i} x\right)}{a^{i}}<\infty
$$

or

$$
\Phi(x):=\sum_{i=0}^{\infty} a^{3 i} \phi\left(\frac{x}{a^{i}}\right)<\infty
$$

for all $x \in X \backslash\{0\}$. For any given mapping $f: V \rightarrow Y$, if there exists a mapping $F: V \rightarrow Y$ satisfying the inequality

$$
\|f(x)-F(x)\| \leq \Phi(x)
$$


for all $x \in V \backslash\{0\}$ and the condition (6) for all $x \in V$, then $F$ is a unique mapping satisfying the conditions (6) and (10).

Proof If $\phi$ satisfies (8), then we have

$$
\lim _{n \rightarrow \infty} \frac{\Phi\left(a^{n} x\right)}{a^{n}}=\lim _{n \rightarrow \infty} \sum_{i=0}^{\infty} \frac{\phi\left(a^{n+i} x\right)}{a^{n+i}}=\lim _{n \rightarrow \infty} \sum_{i=n}^{\infty} \frac{\phi\left(a^{i} x\right)}{a^{i}}=0,
$$

i.e., $\Phi$ satisfies the condition (1) for all $x \in V \backslash\{0\}$.

For the case when $\phi$ satisfies (9), it holds that

$$
\lim _{n \rightarrow \infty} a^{3 n} \Phi\left(\frac{x}{a^{n}}\right)=\lim _{n \rightarrow \infty} \sum_{i=0}^{\infty} a^{3 n+3 i} \phi\left(\frac{x}{a^{n+i}}\right)=\lim _{n \rightarrow \infty} \sum_{i=n}^{\infty} a^{3 i} \phi\left(\frac{x}{a^{i}}\right)=0,
$$

i.e., $\Phi$ satisfies the condition (4) for all $x \in V \backslash\{0\}$. Hence, our assertion is true in view of Theorem 2.1.

Corollary 2.3 Let $a>1$ be a real constant, let $\phi, \psi: V \backslash\{0\} \rightarrow[0, \infty)$ be functions satisfying each of the following conditions:

$$
\begin{aligned}
& \sum_{i=0}^{\infty} a^{i} \psi\left(\frac{x}{a^{i}}\right)<\infty, \quad \sum_{i=0}^{\infty} \frac{\phi\left(a^{i} x\right)}{a^{2 i}}<\infty, \\
& \tilde{\Phi}(x):=\sum_{i=0}^{\infty} a^{i} \phi\left(\frac{x}{a^{i}}\right)<\infty, \quad \tilde{\Psi}(x):=\sum_{i=0}^{\infty} \frac{\psi\left(a^{i} x\right)}{a^{2 i}}<\infty
\end{aligned}
$$

for all $x \in V \backslash\{0\}$, and let $f: V \rightarrow Y$ be an arbitrarily given mapping. If there exists a mapping $F: V \rightarrow Y$ satisfying the inequality

$$
\|f(x)-F(x)\| \leq \tilde{\Phi}(x)+\tilde{\Psi}(x)
$$

for all $x \in V \backslash\{0\}$ and the condition (6) for all $x \in V$, then $F$ is a unique mapping satisfying the conditions (6) for all $x \in V$ and the inequality (12) for all $x \in V \backslash\{0\}$.

Proof If we put $\Phi(x)=\tilde{\Phi}(x)+\tilde{\Psi}(x)$, then it follows from (12) that

$$
\frac{1}{a^{4 n}} \Phi\left(a^{2 n} x\right)=\sum_{i=0}^{\infty} \frac{1}{a^{4 n-i}} \phi\left(a^{2 n-i} x\right)+\sum_{i=0}^{\infty} \frac{1}{a^{4 n+2 i}} \psi\left(a^{2 n+i} x\right)
$$

for all $x \in V \backslash\{0\}$. We make a change of the summation indices in the preceding equality with $j=i-2 n$ and $k=2 n+i$ to get

$$
\begin{aligned}
& \frac{1}{a^{4 n}} \Phi\left(a^{2 n} x\right) \\
& \quad=\frac{1}{a^{2 n}} \sum_{j=-2 n}^{\infty} a^{j} \phi\left(\frac{x}{a^{j}}\right)+\sum_{k=2 n}^{\infty} \frac{1}{a^{2 k}} \psi\left(a^{k} x\right) \\
& \quad=\frac{1}{a^{2 n}} \sum_{i=1}^{2 n} \frac{1}{a^{i}} \phi\left(a^{i} x\right)+\frac{1}{a^{2 n}} \sum_{i=0}^{\infty} a^{i} \phi\left(\frac{x}{a^{i}}\right)+\sum_{i=2 n}^{\infty} \frac{1}{a^{2 i}} \psi\left(a^{i} x\right)
\end{aligned}
$$




$$
\begin{aligned}
& =\frac{1}{a^{n}} \sum_{i=1}^{n-1} \frac{a^{i}}{a^{n}} \frac{1}{a^{2 i}} \phi\left(a^{i} x\right)+\sum_{i=n}^{2 n} \frac{a^{i}}{a^{2 n}} \frac{1}{a^{2 i}} \phi\left(a^{i} x\right)+\frac{1}{a^{2 n}} \tilde{\Phi}(x)+\sum_{i=2 n}^{\infty} \frac{1}{a^{2 i}} \psi\left(a^{i} x\right) \\
& \leq \frac{1}{a^{n}} \sum_{i=1}^{\infty} \frac{1}{a^{2 i}} \phi\left(a^{i} x\right)+\sum_{i=n}^{\infty} \frac{1}{a^{2 i}} \phi\left(a^{i} x\right)+\frac{1}{a^{2 n}} \tilde{\Phi}(x)+\sum_{i=2 n}^{\infty} \frac{1}{a^{2 i}} \psi\left(a^{i} x\right)
\end{aligned}
$$

for any $x \in V \backslash\{0\}$. Hence, it follows from (11) that

$$
\lim _{n \rightarrow \infty} \frac{1}{a^{4 n}} \Phi\left(a^{2 n} x\right)=0
$$

for all $x \in V \backslash\{0\}$. On the other hand, we use the above equality to get

$$
\lim _{n \rightarrow \infty} \frac{1}{a^{4 n+2}} \Phi\left(a^{2 n+1} x\right)=\frac{1}{a^{2}} \lim _{n \rightarrow \infty} \frac{1}{a^{4 n}} \Phi\left(a^{2 n} a x\right)=0
$$

for all $x \in V \backslash\{0\}$. From the above two equalities, we conclude that

$$
\lim _{n \rightarrow \infty} \frac{1}{a^{2 n}} \Phi\left(a^{n} x\right)=0
$$

for all $x \in V \backslash\{0\}$.

Similarly, we have

$$
a^{2 n} \Phi\left(\frac{x}{a^{2 n}}\right)=\sum_{i=0}^{\infty} a^{2 n+i} \phi\left(\frac{x}{a^{2 n+i}}\right)+\sum_{i=0}^{\infty} \frac{1}{a^{2 i-2 n}} \psi\left(a^{i-2 n} x\right)
$$

for all $x \in V \backslash\{0\}$. If we make a change of the summation indices in the last equality with $j=i+2 n$ and $k=i-2 n$, then we get

$$
\begin{aligned}
a^{2 n} & \left(\frac{x}{a^{2 n}}\right) \\
& =\sum_{j=2 n}^{\infty} a^{j} \phi\left(\frac{x}{a^{j}}\right)+\frac{1}{a^{2 n}} \sum_{k=-2 n}^{\infty} \frac{1}{a^{2 k}} \psi\left(a^{k} x\right) \\
& =\sum_{i=2 n}^{\infty} a^{i} \phi\left(\frac{x}{a^{i}}\right)+\frac{1}{a^{2 n}} \sum_{i=1}^{2 n} a^{2 i} \psi\left(\frac{x}{a^{i}}\right)+\frac{1}{a^{2 n}} \sum_{i=0}^{\infty} \frac{1}{a^{2 i}} \psi\left(a^{i} x\right) \\
& =\sum_{i=2 n}^{\infty} a^{i} \phi\left(\frac{x}{a^{i}}\right)+\frac{1}{a^{n}} \sum_{i=1}^{n-1} \frac{a^{i}}{a^{n}} a^{i} \psi\left(\frac{x}{a^{i}}\right)+\sum_{i=n}^{2 n} \frac{a^{i}}{a^{2 n}} a^{i} \psi\left(\frac{x}{a^{i}}\right)+\frac{1}{a^{2 n}} \tilde{\Psi}(x) \\
& \leq \sum_{i=2 n}^{\infty} a^{i} \phi\left(\frac{x}{a^{i}}\right)+\frac{1}{a^{n}} \sum_{i=1}^{\infty} a^{i} \psi\left(\frac{x}{a^{i}}\right)+\sum_{i=n}^{\infty} a^{i} \psi\left(\frac{x}{a^{i}}\right)+\frac{1}{a^{2 n}} \tilde{\Psi}(x)
\end{aligned}
$$

for any $x \in V \backslash\{0\}$. Thus, it follows from (11) that

$$
\begin{aligned}
& \lim _{n \rightarrow \infty} a^{2 n} \Phi\left(\frac{x}{a^{2 n}}\right)=0, \\
& \lim _{n \rightarrow \infty} a^{2 n+1} \Phi\left(\frac{x}{a^{2 n+1}}\right)=a \lim _{n \rightarrow \infty} a^{2 n} \Phi\left(\frac{1}{a^{2 n}} \frac{x}{a}\right)=0
\end{aligned}
$$


for each $x \in V \backslash\{0\}$. Thus, we see that

$$
\lim _{n \rightarrow \infty} a^{n} \Phi\left(\frac{x}{a^{n}}\right)=0
$$

for each $x \in V \backslash\{0\}$.

Altogether, $\Phi$ satisfies (2) for all $x \in V \backslash\{0\}$. Hence, Theorem 2.1 implies that our conclusion of this corollary is true.

Corollary 2.4 Let $a>1$ be a real constant, let $\phi, \psi: V \backslash\{0\} \rightarrow[0, \infty)$ be functions satisfying each of the following conditions:

$$
\begin{aligned}
& \sum_{i=0}^{\infty} a^{2 i} \psi\left(\frac{x}{a^{i}}\right)<\infty, \quad \sum_{i=0}^{\infty} \frac{\phi\left(a^{i} x\right)}{a^{3 i}}<\infty, \\
& \tilde{\Phi}(x):=\sum_{i=0}^{\infty} a^{2 i} \phi\left(\frac{x}{a^{i}}\right)<\infty, \quad \tilde{\Psi}(x):=\sum_{i=0}^{\infty} \frac{\psi\left(a^{i} x\right)}{a^{3 i}}<\infty
\end{aligned}
$$

for all $x \in V \backslash\{0\}$, and let $f: V \rightarrow Y$ be an arbitrarily given mapping. If there exists a mapping $F: V \rightarrow Y$ satisfying the inequality

$$
\|f(x)-F(x)\| \leq \tilde{\Phi}(x)+\tilde{\Psi}(x)
$$

for all $x \in V \backslash\{0\}$ and the condition (6) for all $x \in V$, then $F$ is a unique mapping satisfying the conditions (6) for all $x \in V$ and (14) for all $x \in V \backslash\{0\}$.

Proof If we put $\Phi(x)=\tilde{\Phi}(x)+\tilde{\Psi}(x)$, then it follows from (13) that

$$
\frac{1}{a^{6 n}} \Phi\left(a^{2 n} x\right)=\sum_{i=0}^{\infty} \frac{1}{a^{6 n-2 i}} \phi\left(a^{2 n-i} x\right)+\sum_{i=0}^{\infty} \frac{1}{a^{6 n+3 i}} \psi\left(a^{2 n+i} x\right)
$$

for all $x \in V \backslash\{0\}$. We make a change of the summation indices in the preceding equality with $j=i-2 n$ and $k=2 n+i$ to get

$$
\begin{aligned}
& \frac{1}{a^{6 n}} \Phi\left(a^{2 n} x\right) \\
& \quad=\frac{1}{a^{2 n}} \sum_{j=-2 n}^{\infty} a^{2 j} \phi\left(\frac{x}{a^{j}}\right)+\sum_{k=2 n}^{\infty} \frac{1}{a^{3 k}} \psi\left(a^{k} x\right) \\
& \quad=\frac{1}{a^{2 n}} \sum_{i=1}^{2 n} \frac{1}{a^{2 i}} \phi\left(a^{i} x\right)+\frac{1}{a^{2 n}} \sum_{i=0}^{\infty} a^{2 i} \phi\left(\frac{x}{a^{i}}\right)+\sum_{i=2 n}^{\infty} \frac{1}{a^{3 i}} \psi\left(a^{i} x\right) \\
& \quad=\frac{1}{a^{n}} \sum_{i=1}^{n-1} \frac{1}{a^{2 i+n}} \phi\left(a^{i} x\right)+\sum_{i=n}^{2 n} \frac{1}{a^{2 n+2 i}} \phi\left(a^{i} x\right)+\frac{1}{a^{2 n}} \tilde{\Phi}(x)+\sum_{i=2 n}^{\infty} \frac{1}{a^{3 i}} \psi\left(a^{i} x\right) \\
& \leq \frac{1}{a^{n}} \sum_{i=1}^{\infty} \frac{1}{a^{3 i}} \phi\left(a^{i} x\right)+\sum_{i=n}^{\infty} \frac{1}{a^{3 i}} \phi\left(a^{i} x\right)+\frac{1}{a^{2 n}} \tilde{\Phi}(x)+\sum_{i=2 n}^{\infty} \frac{1}{a^{3 i}} \psi\left(a^{i} x\right)
\end{aligned}
$$


for any $x \in V \backslash\{0\}$. Hence, by (13), we get

$$
\lim _{n \rightarrow \infty} \frac{1}{a^{6 n}} \Phi\left(a^{2 n} x\right)=0
$$

for all $x \in V \backslash\{0\}$. On the other hand, we use the above equality to get

$$
\lim _{n \rightarrow \infty} \frac{1}{a^{6 n+3}} \Phi\left(a^{2 n+1} x\right)=\frac{1}{a^{3}} \lim _{n \rightarrow \infty} \frac{1}{a^{6 n}} \Phi\left(a^{2 n} a x\right)=0
$$

for all $x \in V \backslash\{0\}$.

From the above two equalities, we conclude that

$$
\lim _{n \rightarrow \infty} \frac{1}{a^{3 n}} \Phi\left(a^{n} x\right)=0
$$

for all $x \in V \backslash\{0\}$.

Similarly, we have

$$
a^{4 n} \Phi\left(\frac{x}{a^{2 n}}\right)=\sum_{i=0}^{\infty} a^{4 n+2 i} \phi\left(\frac{x}{a^{2 n+i}}\right)+\sum_{i=0}^{\infty} \frac{1}{a^{3 i-4 n}} \psi\left(a^{i-2 n} x\right)
$$

for all $x \in V \backslash\{0\}$. If we make a change of the summation indices in the last equality with $j=i+2 n$ and $k=i-2 n$, then we get

$$
\begin{aligned}
a^{4 n} & \left(\frac{x}{a^{2 n}}\right) \\
& =\sum_{j=2 n}^{\infty} a^{2 j} \phi\left(\frac{x}{a^{j}}\right)+\frac{1}{a^{2 n}} \sum_{k=-2 n}^{\infty} \frac{1}{a^{3 k}} \psi\left(a^{k} x\right) \\
& =\sum_{i=2 n}^{\infty} a^{2 i} \phi\left(\frac{x}{a^{i}}\right)+\frac{1}{a^{2 n}} \sum_{i=1}^{2 n} a^{3 i} \psi\left(\frac{x}{a^{i}}\right)+\frac{1}{a^{2 n}} \sum_{i=0}^{\infty} \frac{1}{a^{3 i}} \psi\left(a^{i} x\right) \\
& =\sum_{i=2 n}^{\infty} a^{2 i} \phi\left(\frac{x}{a^{i}}\right)+\frac{1}{a^{n}} \sum_{i=1}^{n-1} \frac{a^{i}}{a^{n}} a^{2 i} \psi\left(\frac{x}{a^{i}}\right)+\sum_{i=n}^{2 n} \frac{a^{i}}{a^{2 n}} a^{2 i} \psi\left(\frac{x}{a^{i}}\right)+\frac{1}{a^{2 n}} \tilde{\Psi}(x) \\
& \leq \sum_{i=2 n}^{\infty} a^{2 i} \phi\left(\frac{x}{a^{i}}\right)+\frac{1}{a^{n}} \sum_{i=1}^{\infty} a^{2 i} \psi\left(\frac{x}{a^{i}}\right)+\sum_{i=n}^{\infty} a^{2 i} \psi\left(\frac{x}{a^{i}}\right)+\frac{1}{a^{2 n}} \tilde{\Psi}(x)
\end{aligned}
$$

for any $x \in V \backslash\{0\}$. Thus, we obtain

$$
\begin{aligned}
& \lim _{n \rightarrow \infty} a^{4 n} \Phi\left(\frac{x}{a^{2 n}}\right)=0, \\
& \lim _{n \rightarrow \infty} a^{4 n+2} \Phi\left(\frac{x}{a^{2 n+1}}\right)=a^{2} \lim _{n \rightarrow \infty} a^{4 n} \Phi\left(\frac{1}{a^{2 n}} \frac{x}{a}\right)=0
\end{aligned}
$$

for each $x \in V \backslash\{0\}$. Thus, we see that

$$
\lim _{n \rightarrow \infty} a^{2 n} \Phi\left(\frac{x}{a^{n}}\right)=0
$$

for each $x \in V \backslash\{0\}$. 
Altogether, $\Phi$ satisfies (3) for all $x \in V \backslash\{0\}$. Hence, Theorem 2.1 implies that our conclusion of this corollary is true.

\section{Applications}

In this section, we apply the theorem and corollaries of the last section to show that if for any given mapping $f$, there exists an additive, a quadratic, a cubic, a quadratic-additive, a cubic-additive, a cubic-quadratic, or a cubic-quadratic-additive mapping $F$ near $f$, then the mapping $F$ is uniquely determined.

The proofs of the first three corollaries immediately follow from Corollaries 2.2, 2.3, and 2.4, respectively, because each cubic-quadratic-additive mapping satisfies the conditions in (6) provided $a$ is a rational number.

Corollary 3.1 Let $a>1$ be a rational number and let $\phi: V \backslash\{0\} \rightarrow[0, \infty)$ be a function satisfying the condition (8) or (9) for all $x \in V \backslash\{0\}$. Let $f: V \rightarrow Y$ be a given mapping. If there exists a cubic-quadratic-additive mapping $F: V \rightarrow Y$ satisfying the inequality (10), then $F$ is uniquely determined.

Corollary 3.2 Let $a>1$ be a rational number and let $\phi, \psi: V \backslash\{0\} \rightarrow[0, \infty)$ be functions satisfying the conditions in (11) for all $x \in V \backslash\{0\}$. Let $f: V \rightarrow Y$ be a given mapping. If there exists a cubic-quadratic-additive mapping $F: V \rightarrow Y$ satisfying the inequality (12), then $F$ is uniquely determined.

Corollary 3.3 Let $a>1$ be a rational number and let $\phi, \psi: V \backslash\{0\} \rightarrow[0, \infty)$ be functions satisfying the conditions in (13) for all $x \in V \backslash\{0\}$. Let $f: V \rightarrow Y$ be a given mapping. If there exists a cubic-quadratic-additive mapping $F: X \rightarrow Y$ satisfying the inequality (14), then $F$ is uniquely determined.

If $p<1$ then $\Phi(x):=K\|x\|^{p}$ satisfies (1); if $1<p<2$ then $\Phi(x)$ satisfies (2); if $2<p<3$ then $\Phi(x)$ satisfies (3); and if $p>3$ then $\Phi(x)$ satisfies (4). Hence, by Theorem 2.1, we get the following corollaries concerning the Hyers-Ulam-Rassias stability. For the detailed concept of the Hyers-Ulam-Rassias stability, we refer to [1, 2, 4, 6, 17].

When we prove the Hyers-Ulam-Rassias stability, $Y$ is usually assumed to be a Banach space. In this paper, however, we only need to assume that $Y$ is a real normed space provided the validity of inequality (5), (10), (12), (14), or (15) is already guaranteed.

Corollary 3.4 Let $p \notin\{1,2,3\}$ and $\theta>0$ be real constants, let $X, Y$ be real normed spaces, and let $f: X \rightarrow Y$ be an arbitrarily given mapping. If there exists a mapping $F: X \rightarrow Y$ satisfying the inequality

$$
\|f(x)-F(x)\| \leq \theta\|x\|^{p}
$$

for all $x \in X \backslash\{0\}$ and the conditions in (6) for all $x \in X$, then $F$ is a unique mapping satisfying the conditions in (6) for all $x \in X$ and the inequality (15) for all $x \in X \backslash\{0\}$.

Since each of the cubic, additive, and cubic-additive mappings satisfies the conditions in (6), using Corollary 3.2, we can easily prove the following corollary. 
Corollary 3.5 Let $p \notin\{1,2,3\}$ and $\theta>0$ be real constants, let $X, Y$ be real normed spaces, and let $f: X \rightarrow Y$ be an arbitrarily given mapping. If there exists an additive, a quadratic, a cubic, a quadratic-additive, a cubic-additive, a cubic-quadratic, or a cubic-quadraticadditive mapping $F: X \rightarrow Y$ satisfying the inequality (15) for all $x \in X \backslash\{0\}$, then $F$ is uniquely determined.

If we set $\phi(x)=\varepsilon$ in Corollary 3.1, then $\phi$ satisfies the condition (8). Hence, Corollary 3.1 implies the following result.

Corollary 3.6 Let $V$ be a real vector space, let $Y$ be a real normed space, and let $f$ : $V \rightarrow Y$ be an arbitrarily given mapping. If there exists an additive, a quadratic, a cubic, a quadratic-additive, a cubic-additive, a cubic-quadratic, or a cubic-quadratic-additive mapping $F: X \rightarrow Y$ satisfying the inequality

$$
\|f(x)-F(x)\| \leq \varepsilon
$$

for all $x \in V \backslash\{0\}$ and for some $\varepsilon>0$, then $F$ is uniquely determined.

Remark 3.7 In 2005, Baker [3] proved the Hyers-Ulam stability of a large class of functional equations of the form

$$
\sum_{k=0}^{m} f_{k}\left(\alpha_{k} x+\beta_{k} y\right)=0
$$

which includes the additive, the quadratic, the cubic, the quadratic-additive, the cubicadditive, the cubic-quadratic, and the cubic-quadratic-additive type functional equations; in fact, he proved the Hyers-Ulam stability of equation (16) without addressing the uniqueness of the relevant solution of that equation, while the main aim of this paper is to prove a general uniqueness theorem for those equations. From this viewpoint, we can say that this paper complements the results of Baker.

Competing interests

The authors declare that they have no competing interests.

Authors' contributions

All authors contributed equally to the writing of this paper. All authors read and approved the final manuscript.

Author details

'Department of Mathematics Education, Gongju National University of Education, Gongju, 32553, Republic of Korea.

${ }^{2}$ Mathematics Section, College of Science and Technology, Hongik University, Sejong, 30016, Republic of Korea.

\section{Acknowledgements}

Soon-Mo Jung was supported by Basic Science Research Program through the National Research Foundation of Korea (NRF) funded by the Ministry of Education (No. 2013R1A1A2005557).

Received: 17 December 2015 Accepted: 6 March 2016 Published online: 14 March 2016

\section{References}

1. Ulam, SM: A Collection of Mathematical Problems. Interscience, New York (1960)

2. Hyers, DH: On the stability of the linear functional equation. Proc. Natl. Acad. Sci. USA 27, $222-224$ (1941)

3. Baker, JA: A general functional equation and its stability. Proc. Am. Math. Soc. 183, 1657-1664 (2005)

4. Găvruta, P: A generalization of the Hyers-Ulam-Rassias stability of approximately additive mappings. J. Math. Anal. Appl. 184, 431-436 (1994)

5. Hyers, DH, Isac, G, Rassias, TM: Stability of Functional Equations of Several Variables. Birkhäuser, Basel (1998) 
6. Jung, S-M: Hyers-Ulam-Rassias Stability of Functional Equations in Nonlinear Analysis. Springer Optimization and Its Applications, vol. 48. Springer, New York (2011)

7. Rassias, TM: On the stability of the linear mapping in Banach spaces. Proc. Am. Math. Soc. 72, 297-300 (1978)

8. Bahyrycz, A, Olko, J: On stability of the general linear equation. Aequ. Math. 89, 1461-1476 (2015)

9. Bahyrycz, A, Brzdęk, J, Piszczek, M: On approximately $p$-Wright affine functions in ultrametric spaces. J. Funct. Spaces Appl. 2013, Article ID 723545 (2013)

10. Brzdęk, J: Stability of the equation of the $p$-Wright affine functions. Aequ. Math. 85, 497-503 (2013)

11. Gordji, ME, Gharetapeh, SK, Rassias, JM, Zolfaghari, S: Solution and stability of a mixed type additive, quadratic, and cubic functional equation. Adv. Differ. Equ. 2009, Article ID 826130 (2009)

12. Gordji, ME, Kamyarl, M, Khodaei, H, Shin, DY, Park, C: Fuzzy stability of generalized mixed type cubic, quadratic, and additive functional equation. J. Inequal. Appl. 2011, 95 (2011)

13. Gordji, ME, Khodaie, H: Solution and stability of generalized mixed type cubic, quadratic and additive functional equation in quasi-Banach spaces. Nonlinear Anal. 71, 5629-5643 (2009)

14. Gordji, ME, Savadkouhi, MB: Stability of a mixed type additive, quadratic and cubic functional equation in random normed spaces. Filomat 25, 43-54 (2011)

15. Lee, Y-H: On the generalized Hyers-Ulam stability of the generalized polynomial function of degree 3. Tamsui Oxf. J. Math. Sci. 24, $429-444$ (2008)

16. Park, C: A fixed point approach to the fuzzy stability of an additive-quadratic-cubic functional equation. Fixed Point Theory Appl. 2009, Article ID 918785 (2009)

17. Rassias, TM: On the Stability of the Linear Mapping in Banach Spaces. Springer Optimization and Its Applications, vol. 48. Springer, New York (2011)

18. Szekelyhidi, L: The stability of linear functional equations. C. R. Math. Rep. Acad. Sci. Can. 3(2), 63-67 (1981)

\section{Submit your manuscript to a SpringerOpen ${ }^{\circ}$ journal and benefit from:}

- Convenient online submission

- Rigorous peer review

- Immediate publication on acceptance

- Open access: articles freely available online

- High visibility within the field

- Retaining the copyright to your article 